\title{
ÜLEKÜSIMINE, ÜMBERSÕNASTAMINE JA MITTEMÕISTMINE INFOTELEFONIKÕNEDES
}

\section{Siiri Pärkson}

\begin{abstract}
Ülevaade. Igas inimestevahelises vestluses, sh dialoogis infotelefoni töötaja (infoandja) ja infotelefonile helistaja (kliendi) vahel võib esineda probleeme arusaamisega ning osalejate püüdu nende probleemidega toime tulla. Konversatsioonianalüüsi teoorias on kuulaja poolt esiletõstetud mõistmisprobleeme nimetatud partneri algatatud parandusteks. Eestikeelses suhtluses võib leida kolme erinevat tüüpi partneri algatatud parandusi ning neid nimetatakse vastavalt üleküsimine, ümbersõnastamine ja mittemõistmine. Artiklis uuritakse konversatsioonianalüüsi abil 126 eestikeelset infodialoogi. Ligi pooltes esineb vähemalt üks partneri algatatud parandus. Loomuliku suulise suhtluse mõistmiseks ja rakendamiseks (nt süsteemides, milles arvuti peab inimesega loomulikus keeles suhtlema) on vaja muuhulgas selgeks teha, mis täpselt suhtlusprobleemide tekkimist põhjustab ning milliseid keelelisi struktuure inimesed tegelikult kasutavad, kui nad signaliseerivad probleemi.
\end{abstract}

Võtmesõnad: arvutilingvistika, konversatsioonianalüüs, institutsionaalne suhtlus, suuline kõne, telefonisuhtlus, infodialoogid, üleküsimine, ümbersõnastamine, mittemõistmine, eesti keel

\section{Sissejuhatus}

Tavaliselt on igas vestluses suhtlus- või keelelisi probleeme, mida on vaja lahendada. Konversatsioonianalüüsis (vt ptk 2) nimetatakse sellist probleemide lahendamist paranduseks. Parandust saab algatada nii kõneleja ehk probleemi tootja kui ka vestluspartner ning paranduse saab läbi viia samuti kõneleja või vestluspartner. Käesolevas artiklis on vaatluse all vestluspartneri algatatud parandused.

Artikli teema on tihedalt seotud: 
- eesti dialoogikorpuse (EDiK) arendamisega. Keskendudes dialoogides esinevatele probleemsetele kohtadele, saab arendada edasi dialoogiaktide analüüsi;

- eestikeelse infotelefoniteenuseid osutava dialoogsüsteemi loomisega.

Sissejuhatusele järgnevas peatükis tutvustatakse konversatsioonianalüüsi teooriat ja mõnesid artiklist arusaamiseks olulisi mõisteid. Seejärel antakse ülevaade töös kasutatavast materjalist ja uurimismeetodist. Järgneb analüüs ning iga partneri algatatud paranduse lähem vaatlus. Viimases peatükis esitatakse järeldused ja kokkuvõte.

\section{Teooria}

Salvestatud loomuliku interaktiivse keelekasutuse uurimist nimetavad Ian Hutchby ja Robin Wooffitt (1998: 14) konversatsioonianalüüsiks (ingl conversation analysis, lüh CA). CA tegeleb eeskätt vestluskäitumise regulaarsete mustritega. Eesmärgiks on anda struktuuriliste tunnuste süstemaatiline kirjeldus, mis toetub konkreetsete nähtuste analüüsile (Wooffitt 1990: 20).

Suuline vestlus kahe inimese vahel jaguneb kõnevoorudeks (ingl turn). Kõnevoor on ühe kõneleja jätkuv hälesolek. Tüüpiliselt on teineteisele järgnevatel kõnevoorudel erinevad autorid, kuid ühele kõnelejale võivad kuuluda ka kaks või enam üksteisele järgnevat kõnevooru (nt kui teine kõneleja ei võta talle pakutud kõnevooru, võib esimene kõneleja alustada taas oma kõnevooruga). Kõnevooru vorm, sisu ning pikkus pole ette määratud, vaid on varieerumisvabad (Hutchby, Wooffitt 1998: 47).

Kõnevoorud liigenduvad üksusteks, mida eesti keeles nimetatakse lausungiteks (ingl utterance) ning mille piirid on eelkõige intonatsioonilised, aga ka grammatilis-pragmaatilised (vt Hennoste jt 2002).

Dialoog jaguneb struktuurilt erinevateks väiksemateks ülesanneteks ehk dialoogiaktideks, millest mõned on kergesti lahendatavad (nt teretamisele tervitusega vastamine) ning teised on keerulisemad (nt küsimusele õige vastusega vastamine). EDiK-i märgendamisel on lähtutud muuhulgas põhimõttest, et iga lausung peab omama aktimärgendit, aga võib omada samaaegselt ka mitut märgendit. Kuna lausungi lõppu märgib eeskätt langev intonatsioon, mida märgendatakse punktiga, siis peab iga punktiga lõppev üksus saama aktimärgendi (Hennoste, Rääbis 2004).

EdiK-i märgendamisel on kasutatud Tartu Ülikoolis välja töötatud dialoogiaktide tüpoloogiat (Hennoste, Rääbis 2004) ${ }^{1}$, mis põhineb konversatsioonianalüüsil ning mille järgi jagunevad partneri algatatud parandused (esiliikmed) üleküsimiseks, ümbersõnastamiseks, mittemõistmiseks ja muuks. Need mõisted on defineeritud järgmiselt (Hennoste, Rääbis 2004: 56, 58, 59).

- Üleküsimine (ingl clarification) on akt, mille puhul kuulaja kordab täpselt või väikeste modifikatsioonidega mõnda partneri lausungit, fraasi või sõna, et saada kinnitust selle kohta, et öeldu oli just selline (nt kas te ütlesite niii?).

- Ümbersõnastamine (ingl reformulation) on algatus, mille abil kuulaja pakub oma tõlgenduse (hüpoteesi, ümbersõnastuse, üldistuse, järelduse)

${ }^{1}$ Iga dialoogiakti nimetus (nt RIE: TeRVITUS või ll: TÄPsustamine) koosneb kahest osast: 1) akronüüm, mis sisaldab kas kaks või kolm tähte, millest esimesed kaks näitavad aktirühma (nt RI = rituaalid, IL = infolisa) ning kolmas, mida kasutatakse ainult naaberpaare moodustavate aktide puhul, näitab, kas on tegu naaberpaari esi- või järelliikmega (vastavalt E Või J), 2) akti nimi (nt TERVITUS, TÄPSUSTAMINE).

Viidatud raamat sobib ka käesolevas artiklis esinevate mõistetega tutvumiseks. 
varemöeldu kohta. Tema eesmärgiks on saada kinnitust, kas info mõte oli just selline (nt kas te mõtlesite seda?).

- Mittemõistmine (ingl non-understanding) on akt, millega kuulaja annab teada, et ta ei kuulnud mingit vooru või osa sellest, ei saanud millestki aru või on saadud info tema jaoks nii üllatav, et ta peab vajalikuks seda üle kontrollida.

- Muu (ingl other) hulka kuuluvad paranduse algatused, mis ei mahu toodud süsteemi.

CA järgi on verbaalse suhtluse oluline omadus organiseeritus järjenditena, sekventsidena (ingl sequence). Sekventsiaalsus tähendab seda, kuidas üksteisele järgnevad kõnetoimingud liituvad üksteisega ja milliseid üksteisega seotud tegevuste järjendeid nad moodustavad (Hennoste, Rääbis 2004: 23). Sekventsisüsteemi keskne mõiste on naaberpaar (ingl adjacency pairs). Naaberpaari esiliikme olemasolu nõuab kindlat järelliiget (nt hüvastijätt vastuhüvastijättu jne). Järelliikmed omakorda liigenduvad ootuspärasteks ning ootusevastasteks, mis realiseeruvad üldjuhul keeleliselt erineval kujul (Hennoste jt 2002).

Partneri algatatud parandused kuuluvad naaberpaare moodustavate aktide hulka ning tihti viitavad probleemallika asukohale, lokaliseerivad selle. Seega otsitakse partneri algatatud parandustes uut võimalust probleemkohast arusaamiseks ning samas pakutakse probleemi põhjustajale võimalus olukord ise lahendada. Võimalus eneseparandamiseks antakse isegi siis, kui teatakse viga ja osatakse seda parandada.

Kuna probleemne koht peab alati eelnema parandusele ning asetsema mõnes partneri algatatud parandusele eelnevas kõnevoorus, soovitab Marja-Leena Sorjonen kasutada terminit probleemvoor, mis on kõnevoor, kus probleemne koht asetseb (Sorjonen 1997).

\section{Materjal ja meetod}

Käesolev uurimismaterjal pärineb EDiK-ist, dialoogide analüüsimiseks rakendatakse konversatsioonianalüüsi meetodit. 2007. aasta novembri seisuga on EDiK-is 1061 teksti (178 ooo sõnet), millest 945 on telefonikõned ning 116 silmast-silma vestlused. ${ }^{2}$

EDiK-ist on uurimistöösse valitud juhuslikult 126 dialoogi (8 356 sõna), kuigi on jälgitud, et partneri algatatud paranduste (üleküsimine, ümbersõnastamine, mittemõistmine) protsendiline osakaal oleks enam-vähem vastavuses korpuses esinemise suurusjärguga. Võrdluseks, EdiK-i dialoogides leidub 2007. aasta augusti seisuga kokku 583 (60\%) üleküsimist, 208 (22\%) ümbersõnastamist ning 174 (18\%) mittemõistmist. Kõik valitud dialoogid on infodialoogid, st salvestused klientide telefonikõnedest infotelefonile. Seega on analüüsi all institutsionaalse suhtluse dialoogid.

Artiklis kasutatakse arvandmete esitamisel abivahendina Margus Treumuthi loodud dialoogikorpuse tööpinki. ${ }^{3}$ Lisaks kasutatakse kvantifitseerivaid väljendeid, nagu tihti, üldiselt, korduvalt, suhteliselt harva, tavaliselt jmt. Niisiis on

2 http://math.ut.ee/ koit/Dialoog/EDiC.html (21.11.2007).

3 http://math.ut.ee/ - treumuth/ (08.08.2007). 
kvantitatiivne informatsioon kohati esitatud suhteliselt ebamääraselt, kuid Paul ten Have’i (1999: 144) kinnitust mööda on konversatsioonianalüüsi rakendustes selliste kvantifitseerivate väljendite kasutamine tavaline.

\section{Partneri algatatud parandused infodialoogides}

Artikli uurimismaterjalis esineb partneri algatatud parandusi 60 dialoogis ja 66 dialoogis neid ei leidu. On tähtis mainida, et ühes dialoogis võib esineda rohkem kui üks partneri algatatud parandus (60-st dialoogist 31-s). Samuti võivad ühes dialoogis esineda koos erinevat liiki partneri algatatud parandused (6o-st dialoogist 24-s). Erinevat liiki partneri algatatud parandused võivad olla mitte ainult ühes dialoogis, vaid ka lausa ühes kõnevoorus. 17-s dialoogis esineb ühte liiki partneri algatatud parandust rohkem kui korra. Analüüsitavates dialoogides esineb kokku 121 partneri algatatud parandust (vt tabel 1).

Tabel 1. Partneri algatatud paranduste esinemine analüüsitavates infodialoogides ${ }^{4}$

\begin{tabular}{|l|c|c|c|}
\hline $\begin{array}{l}\text { Partneri algatatud } \\
\text { paranduse esiliige }\end{array}$ & Juhtumite arv & $\begin{array}{c}\text { Juhtumite prot- } \\
\text { sent }\end{array}$ & Dialoogide arv \\
\hline Üleküsimine & 72 & $60 \%$ & 50 \\
\hline Ümbersõnastamine & 25 & $21 \%$ & 20 \\
\hline Mittemõistmine & 21 & $17 \%$ & 18 \\
\hline $\begin{array}{l}\text { Muu (süstematiseerimata } \\
\text { aktid) }\end{array}$ & 3 & $2 \%$ & 3 \\
\hline Kokku & $\mathbf{1 2 1}$ & $\mathbf{1 0 0 \%}$ & $\mathbf{9 1}(\mathbf{6 0})^{5}$ \\
\hline
\end{tabular}

Infodialoogides on 1200 kliendi kõnevooru, infoandja kõnevoore esineb 1527 korda. Põhjus, miks infoandja voorude koguarv on suurem kui kliendi kõnevoorude arv, tuleneb ühelt poolt nn esimeste lausungite distributsiooni reeglist (Schegloff, 1968: 1076, viidatud ten Have 1999: 16 järgi), mille järgi vastaja räägib esimesena. Teisalt on infokõnedele omane, et klient annab märku, millal ta on valmis kõne lópetama ning nii on infoandja sagedamini ka viimase lausungi ütleja.

Tabelist 2 võib näha, et üleküsimisi ning mittemõistmisi on algatanud rohkem klient ehk infotelefonile helistaja, seevastu ümbersõnastamist kasutavad enamasti infoandjad. Partneri algatatud parandusi on rohkem kliendil, kuid see tuleneb eelkõige üleküsimiste rohkusest.

Tabel 2. Partneri algatatud paranduste algatajad ja sagedused

\begin{tabular}{|l|c|c|c|c|}
\hline & Klient & Protsent & Infoandja & Protsent \\
\hline Üleküsimine & 54 & $76 \%$ & $18 \%$ & $38 \%$ \\
\hline Ümbersõnastamine & 4 & $6 \%$ & $21 \%$ & $45 \%$ \\
\hline Mittemõistmine & 13 & $18 \%$ & $8 \%$ & $17 \%$ \\
\hline Kokku & $\mathbf{7 1}$ & $\mathbf{1 0 0} \%$ & $\mathbf{4 7 \%}$ & $\mathbf{1 0 0} \%$ \\
\hline
\end{tabular}


Kõikides analüüsitavates dialoogides on tegu partneri algatatud eneseparandustega. Niisiis võib väita, et eneseparandamise eelistamine ei ole inglise keele spetsiifiline, vaid kehtib samuti eestikeelsetes dialoogides. Seda väidet toetab Krista Strandsoni uurimistööde (Strandson 2000, 2001, 2002) raames läbiviidud argivestluste analüüs, mille järgi 144 vestluskaaslase algatatud parandusest 134 juhul jättis vestluskaaslane paranduse läbiviimise õiguse kõnelejale ning 10 juhul viis vestluskaaslane paranduse ise lõpuni.

\section{1. Üleküsimine}

Vormiliselt võib üleküsimised jaotada otsesteks üleküsimisteks ja modifitseeritud üleküsimisteks.

- Otsene üleküsimine (näide 1$)^{6}$ on siis, kui kõnevoor jääb eelnevaga samaks.

(1) 1. V: kuus? (.) [üks.] | KYJ: INFO ANDMINE || PPJ: LÄBIVIIMINE | 2. H: [kuus] üks. $£$ | KYE: VASTUST PAKKUV | | PPE: ÜLEKÜSIMINE | 3. V: [jah]. | KYJ: JAH | | PPJ: LÄBIVIIMINE |

Näitelõigus 1 kordab klient (rida 2) sõna-sõnalt infoandja (rida 1) kõnevooru.

- Modifitseeritud üleküsimine (näide 2) esineb siis, kui kõneleja kordab eelnevat kõnevooru ning teeb mõned grammatilised ja/või leksikaalsed muudatused. Kõneleja võib lisada mõne fraasi või, vastupidi, võib lühendada eelnevat kõnevooru.

(2) 1. neli neli neli, | DIJ: INFO ANDMINE |

2. (0.5)

3. H: kolm `nelja jah | KYE: VASTUST PAKKUV | | PPE: ÜLEKÜSIMINE | 4. V: jah? | KYJ: JAH | | PPJ: LÄBIVIIMINE |

Kliendi üleküsimine leiab aset enamasti telefoni (või faksi) numbri kordamisel. Infoandja üleküsimine toimub, kui ta pole kindel, et kuulis, mõistis või mäletab korrektselt eelnevalt saadud olulist informatsiooni. Kuulmishäire või tõlgendusraskusena tunduv võib olla ka infoandja poolt aja võitmiseks või planeerimiseks kasutatav vahend. Sel juhul ei pruugi üleküsimise vastus tegelikult rolli mängida, kui sealt just uut informatsiooni ilmsiks ei tule.

Üleküsimine esineb tihti siis, kui rääkija (uuritud dialoogides enamasti klient) usub või näib uskuvat, et ta ei kuule õigesti. Analüüsitud materjalis esineb ainult 3 juhtumit, kus klient kuuleb tõepoolest valesti. Nii väheste juhtumite arv võib viidata ka sellele, et üleküsimine on pigem tava kui vajadus. Kuid infotelefonile helistamise puhul on üleküsimine kindlasti ka funktsionaalne, sest üleküsimist kasutatakse enamasti kontrollimaks andmeid, mis peavad olema täpsed (aadressid, telefoninumbrid, nimed). Üleküsimise põhjused on esitatud tabelis 3 .

Mõnigi kord põhjused veidi kattuvad ning seetõttu on üleküsimiste jaotus tinglik. Lisaks võivad mõned põhjused olla seotud mittekuulmise ja kinnituse otsimisega.

${ }^{6}$ Näidetes on nummerdatud lausungid ning pausid kõnevoorude vahel ehk pausid, mis ei kuulu kummagi kõne- 
Tabel 3. Üleküsimise põhjused

\begin{tabular}{|l|c|}
\hline Põhjus & Juhtumite arv \\
\hline (telefoni/faksi)number & 38 \\
\hline aadress/asukoht & 12 \\
\hline institutsiooni nimi/üldnimi & 8 \\
\hline inimese nimi & 4 \\
\hline info puudumine & 4 \\
\hline ebaootuspärane või üllatav informatsioon & 3 \\
\hline muu & 3 \\
\hline Kokku & $\mathbf{7 2}$ \\
\hline
\end{tabular}

Loetelust on näha, et kõige enam üleküsimisi põhjustab (telefoni/faksi)number, mis iseenesest on infotelefoni dialoogidele väga omane. Aadressi all on mõeldud siin ja edaspidi tänava nime ning maja numbrit; asukoht on laialivalguvam mõiste, mis tähistab näiteks linna, linnajao, tänava nime või muud piirkonda (nt kesklinn, Lõuna-Eesti). Institutsiooni nimi tähistab ametlikku või kõneleja poolt arvatavat ametlikku nime. Üldnimi on nimetus, mis ei ole seotud konkreetse institutsiooniga (nt apteek, loomakliinik).

(Telefoni)numbrite teatamise korral esinevad järgmised reeglipärasused.

- Telefoninumbrit öeldakse osade kaupa (näites 3 read 4, 7, 9), üleküsimise akt toimub pärast viimast numbriosa ning korratakse ainult viimast numbriosa (3, rida 10). See on ka kõige sagedasem üleküsimise muster. Kuulaja omakorda annab numbriosade vahel tagasisidet (akti vR: NEUTRAALNE JÄTKAJA abil; 3, rida 6), et ta on kuuldel ja teine võib jätkata ja/või ta saab öeldust aru. Tagasiside võib väljenduda numbriosa kordamisena (VR: NEUTRAALNE JÄTKAJA; 3, rida 8) või lühikeste ühesõnaliste reageerimistena (jaa?; jah), mida on nimetatud ka minimaaltagasisideks (Hennoste, Rääbis 2004). Reeglipärane on seegi, et kuulaja jääb numbriosade vahel esimesena valitud tagasiside (numbriosa kordamine $v s$. lühikesed ühesõnalised reageerimised) juurde.

(3) 1. H: $£$ öelge palun Tartu migratsiooni`ameti (.) selle telefoni`number. $£$ | DIE: SOOV |

2. V: jaa? | VR: NEUTRAALNE VASTUVÕTUTEADE | 3. üks=`hetk, | DIJ: EDASILÜKKAMINE |

4. (...) .hh `seitse `kolm `seitse, | DIJ: INFO ANDMINE |

5. (.)

6. H: $£$ jaa? $£ \mid$ VR: NEUTRAALNE JÄTKAJA |

7. V: `seitse `viis, | DIJ: INFO ANDMINE |

8. H: $£$ jaa? $£$ | VR: NEUTRAALNE JÄTKAJA |

9. V: ‘kuus `null. | DIJ: INFO ANDMINE |

10. H: $£$ kuus 'null. $=£ \quad \mid$ KYE: VASTUST PAKKUV $|\quad|$ PPE: ÜLEKÜSIMINE |

11. $\mathrm{V}:=\mathrm{jah}=|\mathrm{KYJ}: \mathrm{JAH}| \quad \mid$ PPJ: LÄBIVIIMINE $\mid$ 
- Telefoninumbrit öeldakse osade kaupa (näites 4 ridadel 1, 4, 6), üleküsimise akt toimub pärast viimast numbriosa ning korratakse kogu telefoninumbrit ehk siis järjekorras kõik kuuldud numbriosad (näites 4 real 8). Kuulaja annab tagasisidet ilma uut informatsiooni lisamata ega kõneõigust taotlemata. Tagasiside võib väljenduda numbriosa kordamisena (VR: NEUTRAALNE JÄTKAJA) või lühikeste ühesõnaliste reageerimistena jaa?; jah (VR: NEUTRAALNE JёTKAJA). Üsna tavaline on ka neutraalne jätkaja $m h m h$ (Hennoste, Rääbis 2004: 134), kuid analüüsitud dialoogides selline juhtum puudub.

(4) 1. V: .hh `number, kinnitamata andmetel `seitse, (.) `kolm, `kuus | DIJ: INFO ANDMINE |

2. (o.5)

3. H: jaa? | VR: NEUTRAALNE JÄTKAJA |

4. V: `kuus `seitse, | DIJ: INFO ANDMINE |

5. H: jah | VR: NEUTRAALNE JÄTKAJA |

6. V: seitse=`seitse. | DIJ: INFO ANDMINE |

7. (0.8)

8. H: `seitse `kolm `kuus `kuus `seitse `seitse `seitse. | KYE: VASTUST PAKKUV | | PPE: ÜLEKÜSIMINE |

9. V: jah. | KYJ: JAH | | PPJ: LÄBIVIIMINE |

- Telefoninumbrit öeldakse osade kaupa, üleküsimise akt toimub pärast viimast numbriosa ning selles voorus korratakse ainult viimast numbriosa (vR: NEUTRAALNE VASTUVÕTUTEADE) ja seejärel üleküsimisena kogu telefoninumbrit. Sellise skeemi korral kasutatakse neutraalse jätkajana eelmise numbri kordamist. (Seda mustrit võib pidada ka eelmise punkti erandlikuks alaliigiks, sest selliseid juhtumeid esineb ainult 2.) Näites 5 toimub üleküsimine (rida 8) pärast info andmisi (read 2, 4, 6) ning pärast neutraalse jätkamise ja neutraalse vastuvõtuteate dialoogiakte ( $\operatorname{read} 3,5,7)$.

(5) 1. V: :h `Teguri kolkend `seitse. | DIJ: INFO ANDMINE |

2. `ja: `number=on: > kinnitamata < `andmetel `seitse `kolm `kuus? | DIJ: INFO ANDMINE |

3. H: kolm kuus? | VR: NEUTRAALNE JÄTKAJA |

4. V: seitse öheksa? | DIJ: INFO ANDMINE |

5. H: seitse öheksa? | VR: NEUTRAALNE JÄTKAJA |

6. V: seitse seitse. | DIJ: INFO ANDMINE |

7. H. seitse=seitse, | VR: NEUTRAALNE VASTUVÕTUTEADE |

8. a `kordan seitse kolm `kuus seitse `öheksa seitse seitse. | KYE: VASTUST PAKKUV | | PPE: ÜLEKÜSIMINE |

9. V: jah. | KYJ: JAH | | PPJ: LÄBIVIIMINE |

- Telefoninumber öeldakse välja ühes voorus (vahel võivad olla lühikesed pausid) ning klient või infoandja kordab oma kõnevoorus kogu numbrit (üleküsimine). Näites 6 teavitatakse kogu telefoninumber ühes kõnevoorus (rida 4) ja pärast 0,5-sekundilist pausi (rida 5) toimub kliendi üleküsimine kogu numbri kordamise näol (rida 6). 
(6) 1. V: jaa | VR: NEUTRAALNE VASTUVÕTUTEADE |

2. üks= `hetk, | DIJ: EDASILÜKKAMINE |

3. (...) haigekassal on kli`enditeeninduse 'lühinumber. | DIJ: INFO ANDMINE

4. üks `kuus, (.) `kolm`kuus`kolm. | DIJ: INFO ANDMINE |

5. (0.5)

6. H: üks `kuus?`kolm kuus `kolm [jah] | KYE: VASTUST PAKKUV | | PPE: ÜLEKÜSIMINE |

7. V: [jah.] | KYJ: JAH | | PPJ: LÄBIVIIMINE |

Ülalesitatud üleküsimise variandid kehtivad olenemata sellest, kas numbriosa koosneb 2, 3 või 4 numbrist. Siiski, 2 numbrist koosnemine on kõige tavalisem. Oluline on, et need mustrid kehtivad üksnes juhul, kui numbri ütlemise kestel pole partner algatanud ühtki parandust ning kogu number on saadud ladusalt lõpuni öelda.

EDiK-i tüpoloogiat järgides selgub, et antud artiklis analüüsitud dialoogides on kõik üleküsimised algatatud vastust pakkuva küsimusena, mis eeldab vastust jah või $e i$ (vt tabelit 4). Seejuures jaatav vastus ning nõustuv ei märgivad, et probleem on lahendatud. Samas esineb lisaks jaatusele või eitusele ka täpsustamist, mis võib järgneda jaatusele või eitusele, aga ka jaatuse/eituse asemel, st täpsustamisele ei eelne ega järgne eitust ega jaatust. See on ka põhjus, miks tabelis 4 on algatuste arv (72) väiksem kui parandusaktide arv (78) - ühele parandusalgatusele võib järgneda mitu parandust või täpsustust.

Tabel 4. Üleküsivad parandusaktid (PPE: ÜLEKÜSIMINE)

\begin{tabular}{|l|c|l|c|}
\hline \multicolumn{1}{|c|}{ Algatus } & $\begin{array}{c}\text { Algatuste } \\
\text { arv }\end{array}$ & \multicolumn{1}{|c|}{ Parandusakt } & $\begin{array}{c}\text { Parandusaktide } \\
\text { arv }\end{array}$ \\
\hline KYE: VASTUST PAKKUV & 72 & KYJ: JAH & 64 \\
\cline { 3 - 4 } & & IL: TÄPSUSTAMINE & 10 \\
\cline { 3 - 4 } & & KYJ: El & 3 \\
\cline { 3 - 4 } & & KYJ: NÕUSTUV EI & 1 \\
\hline Kokku & $\mathbf{7 2}$ & & $\mathbf{7 8}$ \\
\hline
\end{tabular}

Enamus üleküsimistest moodustatakse vastust pakkuva sõna või fraasi abil. Põhjuseks on, et enamasti küsitakse üle telefoninumber või osa sellest. Niisiis on nimetatud üleküsimise vorm infotelefonikõnede spetsiifiline. Küsimuse märkimiseks kasutatakse palju sagedamini lausungi lõppu lisatud partiklit jah kui küsipartiklit või/vä. Üleküsimist algatab rohkem klient ning seda sõltumata vormist, milles (vastust pakkuv) küsimus on esitatud.

Juhul kui vastust pakkuv üleküsimine sisaldab tegusõna, mida infodialoogides esineb suhteliselt harva (16 juhtumit), siis peaaegu alati (14 juhtumit) kasutab paranduse algataja oleviku kindlat kõneviisi. Vaid ühel juhtumil kasutatakse lihtmineviku kindlat kõneviisi. 
Tabel 5. Üleküsimist algatava dialoogiakti lingvistiline struktuur?

\begin{tabular}{|l|l|c|}
\hline \multicolumn{1}{|c|}{ Dialoogiakt } & \multicolumn{1}{|c|}{ Lingvistiline struktuur } & Juhtumite arv \\
\hline \multirow{4}{*}{ KYE: VASTUST PAKKUV } & sõna/fraas & 46 \\
\cline { 2 - 3 } & sõna/fraas $+j a h$ & 9 \\
\cline { 2 - 3 } & lause + jah & 6 \\
\cline { 2 - 3 } & lause & 5 \\
\cline { 2 - 3 } & see + lause + jah & 3 \\
\cline { 2 - 3 } & lause + või/vä & 2 \\
\cline { 2 - 3 } & sõna/fraas + vä & 1 \\
\hline \multirow{2}{*}{ Kokku } & & $\mathbf{7 2}$ \\
\hline
\end{tabular}

\section{2. Ümbersõnastamine}

Kui telefoninumbri üleküsimine on infodialoogides isegi ootuspärane, siis (telefoni)numbrite ümbersõnastamine on pigem erandlik ning võib esineda juhtudel, kus järjest on mitu ühesugust numbrit (vt näidet 7) või kui infot antakse mitme (telefoni)numbri kohta, mille algus on sama ja lõpp muutuv.

(7) 1. H: te:re | RIJ: VASTUTERVITUS |

2. $\{--\}$ `Tartus kurgu-nina-kõrva kliiniku registra `tuuri `telefoni`numbrit. | DIE: SOOV |

3. V: jah? | VR: NEUTRAALNE VASTUVÕTUTEADE |

4. üks=`hetk, | DIJ: EDASILÜKKAMINE |

5. (2.0)

6. V: ‘registra `tuur on: seitse (.) kolm üks? | DIJ: INFO ANDMINE |

7. (o.8)

8. H: jaa? | VR: NEUTRAALNE JÄTKAJA |

9. V: üheksa seitse, (o.8) seitse seitse. | DIJ: INFO ANDMINE |

10. (1.0)

11. H: > kolm seitset on lõpus=sis, < | KYE: VASTUST PAKKUV | | PPE: ÜMBERSÕNASTAMINE |

12. V: jah. | KYJ: JAH | | PPJ: LÄBIVIIMINE |

Näites 7 soovib klient kliiniku registratuuri telefoninumbrit (rida 2). Infoandja alustab numbri ütlemist real 6 ja lõpetab real 9. Sellele järgneb kliendi algatatud numbriosa ümbersõnastamine real 11.

Ümbersõnastamine võib näidata, millises osas on ümbersõnastaja teadmistes või arusaamises lünk, mis vajab täitmist.

- Institutsiooni nimi põhjustab ümbersõnastamist iseäranis juhul, kui nimi on konsonantidest koonev lühend (nt PFT) või kuulajal tekib õigekirja suhtes kahtlus - siis tuleb vajalikke komponente täpsustada ning see viib ümbersõnastamiseni. Tõenäoliselt nõuavad ümbersõnastamist (ja ka teisi partneri parandusalgatusi) sagedamini nimed, kus on eeldatav inglise keele mõju.

7 Fraasiks on loetud kahe, kolme või enama numbri loetelu. Lause tunnuseks on verbi olemasolu. 
(8) 1. V: .hh kas=ee `Farma on `efiga või pee=`hashsh. | KYE: ALTERNATIIV | | VTE: VASTUSE TINGIMUSTE TÄPSUSTAMINE | 2. H: ee `ei, `Farma=nagu (.) nagu: | KYJ: MUU | | VTJ: VASTUSE TINGIMUSTE TÄPSUSTAMINE

3. V: `ef `aa `er `em `aa.= | KYE: VASTUST PAKKUV | | PPE: ÜMBERSÕNASTAMINE |

4. H: =just | KYJ: JAH | | PPJ: LÄBIVIIMINE |

Näitelõigus 8 on infoandja ümbersõnastamise (rida 3) põhjuseks firma nime õigekiri (read 1 ja 2).

- Kui info andmisel on olemas asukoht või aadress, siis peab soov sisaldama ka institutsiooni või selle üldnime. (Teoreetiliselt on võimalik variant, kus institutsiooni nime/üldnime ei esine, nt Öelge, mis firma asub sel aadressil, kuid uuritava materjali hulgas selline juhtum puudub.) Mõnikord on aga üldnime asemel kasutatud tegevust (nt ujula, veekeskus - ujuma). Sellistel juhtudel võib infoandja tegevuse sõnastada ümber institutsiooni üldnimeks.

(9) 1. H: te:re. | RIJ: VASTUTERVITUS |

2. paluksin teada `Tartus on võimalik `Mõisavahe tänaval `soolaravi teha. | DIE: SOOV |

3. $\mathrm{t}=$ ega te ei=oska seal kontaktnaa- `numbrit anda. | KYE: JUTUSTAV KAS |

4. V: `soolakambrid jah? | KYE: VASTUST PAKKUV | | PPE: ÜMBERSÕNASTAMINE |

5. H: jah | KYJ: JAH | | PPJ: LÄBIVIIMINE |

Näites 9 soovib klient teada, kas Mõisavahe tänaval on võimalik soolaravi teha (rida 2). Infoandja sõnastab tegevuse soolaravi teha ümber üldnimeks soolakamber (rida 4). Ümbersõnastamine on seotud helistaja öeldud andmete viimisega andmebaasis kasutatavale kujule (nt soolaravi $\rightarrow$ soolakambrid).

Infoandja ümbersõnastamised ongi enamasti seotud otsesemalt või kaudsemalt andmebaasiga (andmebaasi struktuur või andmete õigekiri). Infoandja muudab sisusõnu (nt soolaravi $\rightarrow$ soolakamber; Kaa salong $\rightarrow$ Kaa arvutisalong) või lisab teavet (nt Elmar $\rightarrow$ raadio Elmar). Kliendi ümbersõnastamised on seotud mõnes eelnevas voorus kuuldud teabe kordamise ehk faktide täpsustamisega.

Ilmneb, et ümbersõnastamist kasutades soovib infoandja aidata nii klienti kui ennast. Ühelt poolt annab ümbersõnastamine teavet, kas ümbersõnastatud kõnevooru on õigesti mõistetud. Teisalt arendab see vestlust ning viib lähemale suhtluseesmärgi saavutamisele. Ümbersõnastamine on niisiis oluline lüli kõnevooru mõistmise ning dialoogi arengu vahel.

Erinevalt teistest partneri algatatud parandustest algatab ümbersõnastamise enamasti infoandja. Selle põhjuseks on infotelefoni vestluste omapära, kus infotöötaja peab andmebaasist leidma vajaliku info ja kasutab ümbersõnastamist kinnituse saamiseks, et ta asub otsima õiget (vajalikku) teavet. Infoandja ümbersõnastamine on lühem kui eelnev kliendi kõnevoor, sest infoandja teeb eelmisest kõnevoorust kokkuvõtte, korrastab ja kohandab eelmise kõnevooru andmed andmebaasi struktuurile vastavaks. 
Mõlemad, nii infoandja kui klient, algatavad ümbersõnastamise enamasti vastust pakkuva küsimusena. Enamjaolt järgneb sellele järgmises kõnevoorus jaatus (nõustuv ei täidab seejuures sama rolli mis jaatamine). Vahel lisatakse ka täpsustavat infot, harvem vastatakse ümbersõnastamisele eitusega või informatsiooni andmisega. Tähelepanu väärib, et parandus iseseisvalt puht täpsustamisena ei esine, st täpsustamisele peab eelnema kinnitamine või ümberlükkamine (siin erineb ümbersõnastamine üleküsimisest).

Tabel 6. Ümbersõnastavad aktid (PPE: ÜMBERSÕNASTAMINE)

\begin{tabular}{|l|c|l|r|c|}
\hline \multicolumn{1}{|c|}{ Algatus } & Arv & \multicolumn{1}{|c|}{ Parandus } & Arv & Protsent \\
\hline \multirow{3}{*}{ KYE: VASTUST PAKKUV } & \multirow{2}{*}{24} & KYJ: JAH & 19 & $61,3 \%$ \\
\cline { 3 - 5 } & & IL: TÄPSUSTAMINE & 6 & $19,4 \%$ \\
\cline { 3 - 5 } & & KYJ: EI & 3 & $9,7 \%$ \\
\cline { 3 - 5 } & & KYJ: INFO ANDMINE & 1 & $3,2 \%$ \\
\cline { 3 - 5 } & & KYJ: MUU & 1 & $3,2 \%$ \\
\hline KYE: SULETUD KAS & 1 & KYJ: NÕUSTUV EI & 1 & $3,2 \%$ \\
\hline Kokku & $\mathbf{2 5}$ & & $\mathbf{3 1}$ & $\mathbf{1 0 0} \%$ \\
\hline
\end{tabular}

Sarnaselt üleküsimisele on ka ümbersõnastamise korral võimalik, et ühele parandusalgatusele järgneb mitu paranduse läbiviimist. Tähtis on siiski mainida, et võimalik on ka vastupidine, st esineb mitu partneri parandusalgatust (nt ümbersõnastamist), millele järgneb üks läbiviimine, kuigi sellised juhtumid on harvad (analüüsitud materjalis ainult 1 juhtum).

Ümbersõnastamise moodustamiseks on mitmeid võimalusi (vt tabelit 7), mis on struktuurilt sarnased üleküsimise moodustamisele. Enamikel juhtumitel kasutatakse oleviku kindlat kõneviisi, vaid ühel juhtumil kasutatakse lihtmineviku vormi.

Tabel 7. Ümbersõnastamist algatavate dialoogiaktide lingvistiline struktuur ${ }^{8}$

\begin{tabular}{|l|l|c|}
\hline \multicolumn{1}{|c|}{ Dialoogiakt } & \multicolumn{1}{|c|}{ Lingvistiline struktuur } & Juhtumite arv \\
\hline \multirow{5}{*}{ KYE: VASTUST PAKKUV } & sõna/fraas & 5 \\
\cline { 2 - 3 } & sõna/fraas + jah & 7 \\
\cline { 2 - 3 } & sõna/fraas + või & 2 \\
\cline { 2 - 3 } & lause & 5 \\
\cline { 2 - 3 } & lause + jah & 2 \\
\cline { 2 - 3 } & (tähendab) fraas + jah & 2 \\
\cline { 2 - 3 } & (tähendab) fraas/lause + või & 1 \\
\hline KYE: SULETUD KAS & fraas + jah & $\mathbf{2 5}$ \\
\hline Kokku & & 2 \\
\hline
\end{tabular}

8 Kuna juhtumeid on niivõrd vähe, pole protsente arvutatud. 


\subsection{Mittemõistmine}

Mittemõistmise põhjuseks on, et infoandja või klient ei kuule või ei mäleta olulist osa suhtluspartneri eelmisest kõnevoorust selle infokülluse tõttu. Mittemõistmist võib põhjustada lause, sõna või hääldamisest tekkiv mitmetähenduslikkus. Teisalt ei ole mittemõistmiseks vaja mitmeti mõistetavat lausungit, piisab, kui üks kõneleja leiab, et teine ütles midagi ebatõest või mittesobilikku. Lisaks kasutatakse mittemõistmist mittekuulmise märkimiseks.

Tabel 8. Mittemõistmise algatamise sisulised põhjused

\begin{tabular}{|l|l|c|}
\hline \multicolumn{1}{|c|}{ Dialoogiakt } & \multicolumn{1}{|c|}{ Põhjus } & Juhtumite arv \\
\hline PPE: MITTEMÕISTMINE & telefoni/faksi number & 9 \\
\cline { 2 - 3 } & institutsiooni nimi/üldnimi & 7 \\
\cline { 2 - 3 } & aadress/asukoht & 3 \\
\cline { 2 - 3 } & mittekuulmine/informatsiooni üleküllus & 2 \\
\hline Kokku & & $\mathbf{2 1}$ \\
\hline
\end{tabular}

Tabelis 8 esitatud teabele võib lisada, et mittekuulmine või informatsiooni üleküllus võib olla seotud ka muude esitatud põhjustega, kuid on eraldi välja toodud üksnes siis, kui juhtumit ei saa teiste tabelis 8 nimetatute hulka paigutada.

Kliendi jaoks on peamine probleemiallikas telefoni (või faksi) number. Seejuures esineb mittemõistmist siis, kui infoandja ütleb eelnevas kõnevoorus korraga (ilma tagasisidet ootamata) kogu numbrikombinatsiooni või enam kui kolm numbrit.

Probleemvoorule osutamise ja partneri algatatud paranduse viisid on järgmised.

- Infoandja või klient kordab eelmise vooru lausungist osa, millest ta aru sai, viidates sellega, et soovib teada ülejäänut ehk mõistmatuks jäänud lausungi osa.

(10) 1. V: üks üheksa kuus üks. | DIJ: INFO ANDMINE |

2. (1.2)

3. H: $£$ üks `üheksa? $£$ | KYE: AVATUD | | PPE: MITTEMÕISTMINE |

4. (.)

5. V: kuus? (.) [üks.] | KYJ: INFO ANDMINE || PPJ: LÄBIVIIMINE |

Dialoogikatkes 10 järgneb infoandja telefoninumbri lausumisele (rida 1) pärast 1,2-sekundilist pausi (rida 2) kliendipoolne parandusalgatus (rida 3). Klient kordab tõusva intonatsiooni (märgend ?) ja aktsendiga (märgend $£$...£) esimest kahte numbrit, andes sellega mõista, et järgnevaid numbreid ta kas ei suutnud meelde jätta (nt info üleküllus) või ei saanud aru (nt ei kuulnud). Pärast mikropausi (rida 4) viib infoandja läbi paranduse (rida 5), andes kliendile puuduva teabe.

- Kui probleemiallikat peitev lausung koosneb mitmest erinevast n-ö elemendist (nt ettevõtte nimi + aadress; asukoht + ettevõtte nimi), korratakse seda probleemvooru elementi, mida mõisteti. Sellisel juhul oodatakse ainult selle elemendi piires puuduva info kordamist. 
(11) $1 . \mathrm{H}: £$ [ee] tere. | RIJ: VASTUTERVITUS |

2. (.) `tahtsin küsida `Tartus=e (.) `Kalda tie `kolmkümmend (.) `pleki ‘ukse `koda (.) kas te `saate mu anda. | KYE: JUTUSTAV KAS | 3. (1.2) on sellised (.) \{teil või\} $£ \quad \mid$ KYE: SULETUD KAS | 4. (4.2)

5. V: ja `aadress oli `Kalda `tee? | KYE: AVATUD | | PPE: MITTEMÕISTMINE |

6. (.)

7. H: $£$ `kolmkend kui ma õieti `mäletan. $£$ | KYJ: INFO ANDMINE | | PPJ: LÄBIVIIMINE |

Näites 11 esitab klient pärast vastutervitust (rida 1) jutustava kas-küsimuse abil kolmest elemendist koosneva päringu (rida 2). Need elemendid on asukoht (Tartu), aadress (Kalda tee 3o) ja institutsiooni üldnimi (pleki-ukse-koda). Infoandja küsimus käib ainult ühe elemendi, aadressi kohta (rida 5). Ta lokaliseerib oma mittemõistmise avatud küsimusega: ja `aadress oli `Kalda `tee?, oodates aadressist arusaamatuks jäänud osa kordamist antud elemendis. Klient teeb ootuspärase paranduse (rida 7), kus sarnaselt eelmisele näitele öeldakse üksnes elemendist puuduv osa.

- Probleemsele kohale ei viidata, vaid küsitakse otse. Sellistel juhtumitel on probleemiallikas väga selgelt piiritletud.

(12) 1. H: tere. | RIJ: VASTUTERVITUS |

2. (o.8) öelge (.) kus on Tartus ee `Kaa sa`long. | KYE: AVATUD |

3. (1.5)

4. V: $\mathrm{e}={ }^{\prime}$ kuidas=se sa `long oli | KYE: AVATUD | | PPE: MITTEMÕISTMINE |

5. H: `Kaa. | KYJ: INFO ANDMINE | | PPJ: LÄBIVIIMINE |

6. Kaa sal[ong.] | KYJ: INFO ANDMINE | | PPJ: LÄBIVIIMINE |

Näites 12 koosneb kliendi avatud küsimus (rida 2) kahest elemendist: asukohast (Tartu) ja institutsiooni nimest (Kaa salong). Infoandja algatab mittemõistmise institutsiooni nime suhtes (rida 4), tehes seda antud kontekstis ja suulise kõne vaba vormi arvestades otsese küsimusega: kuidas see salong oli? Kuna dialoogis eelneb ainult üks kõnevoor, siis ei saa kahtlust olla, millele asesõna see osutab. Klient kordab infot kahes järgnevas lausungis (rida 5,6 ). Esimeses lausungis parandab ta väga täpselt (kitsalt) mittemõistmist põhjustanud osa ( $` K a a$.), teises lausungis kordab tervet probleemset elementi ( 'Kaa sal[ong.]).

Mittemõistmine moodustatakse enamasti avatud küsimusena, kuid vahel ka soovina (vt tabelit 9). Paranduse läbiviimised on vormistatud informatsiooni andmisena. Seda nii juhul, kui mittemõistmise algatus on vormistatud avatud küsimusena, kui juhtudel, mil mittemõistmine on algatatud soovi näol.

Sarnaselt teistele partneri algatatud parandustele, võib ka mittemõistmise korral järgneda ühele parandusalgatusele mitu läbiviimise akti. Ilmselt on see inimsuhtlusele omane, et ei parandata ainult vääritimõistetut, vaid vahel jagatakse ka lisateavet või teavet mõne nüansi kohta, kus teine võiks sarnaselt eksida.

Pole ühte ja ainsat kindlat viisi, millega rääkijad väljendaksid mittemõistmist. Kuna vaatluse all on suhteliselt väike arv mittemõistmise juhtumeid, on keeleliste seaduspärasuste märkamine raskendatud. 
Tabel 9. Mittemõistmise puhul kasutatavad parandusaktid (PPE: MITTEMÕISTMINE)

\begin{tabular}{|l|c|c|l|c|c|}
\hline \multicolumn{1}{|c|}{ Algatus } & Arv & Protsent & \multicolumn{1}{c|}{ Parandus } & Arv & Protsent \\
\hline KYE: AVATUD KÜSIMUS & 19 & $90 \%$ & KYJ: INFO ANDMINE & 23 & $88 \%$ \\
\hline DIE: SOOV & 2 & $10 \%$ & DIJ: INFO ANDMINE & 3 & $12 \%$ \\
\hline Kokku & $\mathbf{2 1}$ & $\mathbf{1 0 0} \%$ & & $\mathbf{2 6}$ & $\mathbf{1 0 0} \%$ \\
\hline
\end{tabular}

Nii nagu teised partneri algatatud parandused, käib ka mittemõistmine kas vahetult eelnenud või mõne varem eelnenud kõnevooru kohta. Erinevalt üleküsimisest ja ümbersõnastamisest kasutatakse mineviku vormi enam kui oleviku vormi (vastavalt 7 ja 3 juhtumit), samuti ei lisata lausungi ega kõnevooru lõppu abisõnu jah, või, vä vmt. Mittemõistmist väljendatakse suhteliselt lühidalt, st sõna, fraasi või lühikese lausega:

- $\quad$ (üneem +) küsisõna + sõna/fraas + oli (3 juhtumit);

- $\quad$ sõna (5 juhtumit), millest 3 on avatud tüüpi parandusalgatused (vt tabel 10);

- fraas (6 juhtumit);

- $\quad$ lause (7 juhtumit).

Mitmed fraasid ja laused on vormistatud nn lünkküsimusena ehk lähikontekstis (partneri lausungis) leidub kõneleja fraasis/lauses puuduv osa.

Avatud tüüpi (ingl open class) järgmise kõnevooru parandusalgatus (ingl next turn repair initiation) leiab kasutamist ainult viimase abinõuna, mil vajatakse kõnevooru täielikku uuesti esitamist, sest selline avatud liiki süntaktiline esitus eeldavalt vihjab või osutab, et kõneleja ei ole kuulnud eelmist kõnevooru või piisavalt aru saanud, et korrata midagigi sellest (Clark, Schaefer 1987: 29). Seega ei lokaliseeri avatud tüüpi parandusalgatus probleemi keset ning laieneb kogu eelnenud kõnevoorule. Tabelis 10 on loetletud käesoleva artikli raames uuritud mittemõistmistes leiduvad avatud tüüpi parandusalgatused. (Teistes partneri algatatud parandustes neid ei leidu.)

Tabel 10. Avatud tüüpi parandusalgatused

\begin{tabular}{|l|c|c|}
\hline Parandusalgatuse vahend & Autori tulemused & K. Strandsoni tulemused \\
\hline ah & 2 & 0 \\
\hline kuidas & 1 & 9 \\
\hline mis asi & 1 & 0 \\
\hline hakkame otsast peale & 1 & 0 \\
\hline Kokku & $\mathbf{5}$ & $\mathbf{9}$ \\
\hline
\end{tabular}

Infodialoogides esines 4 erinevat avatud tüüpi mittemõistmise parandusalgatust (ah; kuidas; mis asi; hakkame otsast peale). Materjali vähesed näited kinnitasid Leelo Keevalliku (1999: 49) väidet, et küsiva intonatsiooniga ah moodustab pea alati omaette kõnevooru ja tähendab 'mis sa ütlesid?'.

Krista Strandsoni (2002: 24) ametlikes telefonivestlustes aset leidnud avatud liiki parandusalgatuste loetelu on pikem ( $\mathrm{mh}$; misasja; mida (misse); kuidas; 
vabandust; oi ma ei kuule, kuidas palun; oi mitte ei kuule), kuid peale avatud paranduse kuidas ei esine samuti ühtegi teist parandusalgatuse vahendit üle 2 korra. K. Strandsoni ning käesoleva uurimistöö tulemusi võrreldes selgub tõsiasi, et avatud tüüpi parandusalgatuste loetelu on suhteliselt lai, sest peale sõna kuidas kattuvaid avatud tüüpi parandusalgatusi ei esinenud. Siiski võib nõustuda K. Strandsoni (2002: 35) kokkuvõtva väitega, et "vestluskaaslase avatud tüüpi reformuleeringu algatus osutab vestluskaaslase kuulmisprobleemile, arusaamisraskusele või sellele, et eelmine kõnevoor oli vestluskaaslase jaoks mingil põhjusel ebaootuspärane."

\section{Järeldused ja kokkuvõte}

Suhtlusprobleeme täiesti vältida pole võimalik. Need on üks osa loomulikust inimestevahelisest suhtlemisest. Inimesega loomulikus suulises keeles suhtleva dialoogsüsteemi edukaks töötamiseks on vaja täpselt teada, mis tekitab suhtlusprobleeme, kuidas probleeme vältida ja kuidas tekkinud probleemidega edukalt toime tulla. Just seetõttu on vajalik uurida inimestevahelisi vestlusi. Saades aru inimestevahelise suhtluse iseärasustest, on võimalik seda masinale modelleerida.

Käesolevas artiklis on vaatluse all 126 inimestevahelist suulist infodialoogi eesti dialoogikorpusest. Neist 60 dialoogis leidub üks või enam üleküsimise, ümbersõnastamise, mittemõistmise või muud (ehk süstematiseerimata) dialoogiakti, kokku 121 partneri algatatud parandust. Üleküsimine esineb 72, ümbersõnastamine $25 \mathrm{ja}$ mittemõistmine 21 korda.

Fakt, et peaaegu pooltes dialoogides esineb üks või mitu partneri algatatud parandust, näitab et tegu on tõsise probleemiga dialoogsüsteemi loomise seisukohalt vaadates.

Kõigil partneri algatatud parandustel on omad tunnused, mille poolest nad üksteisele sarnanevad või erinevad. Paljud tunnused on infotelefonikõnede spetsiifilised, nt on iseloomulik numbri üleküsimine. Samuti on välja kujunenud mustrid, mil moel infoandja numbrit ütleb ja kuidas klient numbrist arusaamist väljendab. Samas on numbri ümbersõnastamine harv nähtus. Ümbersõnastamine on tihti seotud kliendi öeldud andmete viimisega infoandja andmebaasis kasutatavale kujule. Nendeks andmeteks on näiteks institutsiooni nimi/üldnimi ja aadress/ asukoht. Mittemõistmist kasutatakse märkimaks, mida partneri öeldust mõistetakse ja mis osa ei mõisteta. Mittemõistmise põhjuseks võib olla näiteks mittekuulmine. Analüüsitud dialoogides põhjustab mittemõistmist enam telefoninumber ja institutsiooni nimi või üldnimi.

Materjalis esinevad kindlad keelelised struktuurid, kuidas üleküsimine, ümbersõnastamine ja mittemõistmine moodustatakse. Seega võib öelda, et kuigi inimestevaheline kõne on spontaanne ja raskesti etteaimatav, panevad institutsioonikõne, infodialoog ja telefonivestlus inimesed rollidesse, mis mõjutavad nende suhtlemist nii, et tekivad teatavad mustrid, kuidas suhtlusprobleemide tekkimisest partnerit teavitatakse.

Partneri algatatud parandused vajavad edaspidi veel uurimist. Nii on näiteks vaja kontrollida, kas käesolevas artiklis esitatud materjalist ilmnenud seaduspärasused, on kehtivad (ja samas vahekorras) ka suurema hulga dialoogide puhul. 
Mark Fišeli dialoogikorpuse tööpink, mida on kasutatud käesolevas töös abivahendina, sisaldab ka automaatset dialoogiaktide märgendajat. Märgendaja töötab statistiliste printsiipide põhjal, mistõttu aktimärgendid ei pruugi alati õiged olla. Seega hetkel töötava märgendaja väljund ei sobi üldiseks kasutamiseks enne, kui inimene-ekspert pole tulemusi üle vaadanud. Edasises uurimistöös tuleb leida reegleid, mis selle automaatse märgendaja täpsust suurendaksid, sh ka partneri algatatud paranduste märgendamisel.

\section{Transkriptsioonimärgid}

$\mathrm{H}$ - klient

$\mathrm{V}-$ infoandja

(.) - mikropaus (0,2 sekundit või lühem)

(...) - mikropausist pikem paus

$(1,2)$ - pausi pikkus sekundites

. - langev intonatsioon

vaadake - terve sõna rõhutus või intonatsiooni tõus

sa 'long - ebatavaline rõhuline silp

$>\ldots<$ (sissepoole osutavad nooled) - kiirendatud lõik

$<\ldots>$ (väljapoole osutavad nooled) - aeglustatud lóik

*...* - muust kõnest vaiksem lõik

$£ \ldots £$ - aktsenti osutavad märgid

@...@ - hääletooni või hääle kvaliteedi muutumine (nt kellegi kõne jäljendamine)

.hhh - häälekas sissehingamine (üks $h$-täht vastab o,1 sekundile)

$[-$ pealerääkimise algus

] - pealerääkimise lõpp

$=-$ kaks iseseisvat üksust on hääldatud kokku

\{või\} - loogeliste sulgude sees on halvasti kuuldud tekstilõik või kõneleja nimi

$\{--\}$ - ebaselgeks jäänud sõna või kõneleja

$\{---\}-$ pikem ebaselgeks jäänud lõik

\section{Kirjandus}

Clark, Herbert H.; Schaefer, Edward F. 1987. Collaborating on contributions to conversations. - Language and Cognitive Processes 12, 19-41.

Ten Have, Paul 1999. Doing Conversation Analysis: A Practical Guide. London: Sage.

Hennoste, Tiit; Rääbis, Andriela 2004. Dialoogiaktid eesti infodialoogides: tüpoloogia ja analüüs. Tartu Ülikooli arvutiteaduse instituut. Tartu: Tartu Ülikooli Kirjastus.

Hennoste, Tiit; Gerassimenko, Olga; Kasterpalu, Riina; Koit, Mare; Rääbis, Andriela; Strandson, Krista; Valdisoo, Maret 2005. Questions in Estonian information dialogues: form and functions. - V. Matousek, P. Mautner (eds). Text, Speech and Dialogue. 6th International Conference TSD 2005. Berlin: Springer-Verlag, 420-427.

Hutchby, Ian; Wooffitt, Robin 1998. Conversation Analysis: Principles, Practices, and Applications. Blackwell Publishing Inc.

Keevallik, Leelo 1999. Informatsioonikäsitluse partikkel ahah telefonivestluses. - Emakeele Seltsi aastaraamat 43. Tartu: ETA Emakeele Selts, 34-56.

Schegloff, Emanuel 1968. Sequencing in conversational sequence. - Gail Jefferson (ed.). Lectures on Conversation. Vol. I. Oxford: Basil Blackwell, 3-11.

Sorjonen, Marja-Leena 1997. Korjausjäsennys. - L. Tainio (toim.). Keskustelunanalyysin perusteet. Tampere: Vastapaino, 111-137. 
Strandson, Krista 200o. Teise vooru reformuleeringud eesti vestlustes. Bakalaureusetöö. Käsikiri Tartu Ülikooli filosoofiateaduskonna eesti keele osakonnas. Tartu: Tartu Ülikool.

Strandson, Krista 2001. Kuidas vestluskaaslane parandusprotsessi algatab? - Keel ja Kirjandus 6, 394-409.

Strandson, Krista. 2002. Vestluskaaslase algatatud reformuleeringud eesti vestlustes: reformuleeringualgatuse vahendeid ja põhjuseid. Magistritöö. Käsikiri Tartu Ülikooli filosoofiateaduskonna eesti keele osakonnas. Tartu: Tartu Ülikool.

Wooffitt, Robin 1990. On the analysis of interaction: an introduction to conversation analysis. - Paul Luff, Nigel Gilbert, David Frohlich (eds). Computers and Conversation. Computers and People Series. London: Academic Press, 7-38.

\section{Võrgumaterjalid}

Eesti Dialoogikorpuse veebileht. http://math.ut.ee/ koit/Dialoog/EDiC.html (21.11.2007). Eesti Dialoogikorpuse tööpink. http://math.ut.ee/ treumuth/ (08.08.2007).

Siiri Pärkson on lõpetanud Tartu Ülikooli eesti kirjanduse kirjanduse erialal. Kaitses 2007. a humanitaarteaduste magistrikraadi arvutilingvistika erialal. On uurinud loovust ja suulises suhtluses kasutatavaid partneri algatatud parandusi.

siiri_parkson@hotmail.com 


\section{CLARIFICATION, REFORMULATION AND NON-UNDERSTANDING IN PHONE CONVERSATIONS}

\section{Siiri Pärkson}

University of Tartu

It is impossible to completely avoid communication problems; they are a part of natural interpersonal communication. For a dialogue system to successfully work with people in natural spoken language, it is important to know what causes these problems, how to avoid them and how to deal with the problems that have appeared. Because of this it is important to study interpersonal conversations. Understanding of the peculiarities of natural interpersonal communication helps us to model artificial dialogue systems.

There are 126 dialogues from the Estonian dialogue corpus under investigation in the present paper. In 60 of these, there are one or many clarifications, reformulations, non-understandings or other (unclassified) dialogue acts, a total of 121 partner-initiated repairs. Clarifications appear 72 times, reformulations 25 times and non-understandings 21 times.

Each type of partner-initiated repair has a set of features which makes us possible to compare them against each other. Many of these features are specific to information telephone calls. Thus, for example, clarification of numbers is very typical to information dialogues. Also, there are certain patterns in which way a number is spoken by information provider and how the client expresses his/her understanding in it. At the same time, reformulation of numbers happens very rarely. Instead, it is usually connected with conversion of information coming from clients to representation used by a database. Examples of such information are institutional name/general name and address/location. Non-understanding is used to indicate which part of information is understood and which part is not. In the analysed dialogues, telephone numbers, institutional names or general names introduce most non-understandings.

There are certain languge structures which are used to make up clarification, reformulation and non-understanding repairs. Hence it can be said that even though a human speech communication is very spontaneous and hard to predict, factors like institutional speech, information dialogue and telephone call put people into roles which introduce a strong impact on the flow their communication. Moreover, certain patterns appear to inform a partner about problems of communication.

Keywords: computational linguistics, conversation analysis, interaction in institutional settings, spoken language, telephone conversation, information dialogues, clarification, reformulation, non-understanding, Estonian 